\title{
Effects of Thermal Simulation on the Creep Fracture of the Mod. 9Cr-1Mo Weld Metal
}

\author{
Chien-Chun Liao ${ }^{1}$, Chu-Chun Wang ${ }^{1}$, Tai-Cheng Chen ${ }^{2,3}{ }^{(\mathbb{C}}$, Ren-Kae Shiue ${ }^{3}$ (1) \\ and Leu-Wen Tsay 1,4,*iD \\ 1 Department of Optoelectronics and Materials Technology, National Taiwan Ocean University, \\ Keelung 20224, Taiwan; jackyliao30@gmail.com (C.-C.L.); welfare0717@laser-station.com (C.-C.W.) \\ 2 Nuclear Fuels and Materials Division, Institute of Nuclear Energy Research, Taoyuan 32546, Taiwan; \\ tcchen@iner.gov.tw \\ 3 Department of Materials Science and Engineering, National Taiwan University, Taipei 10617, Taiwan; \\ rkshiue@ntu.edu.tw \\ 4 Center of Excellence for Ocean Engineering, Taiwan Ocean University, Keelung 20224, Taiwan \\ * Correspondence: b0186@mail.ntou.edu.tw; Tel.: +886-2-2462-2192 (ext. 6405)
}

Received: 31 July 2020; Accepted: 28 August 2020; Published: 2 September 2020

\begin{abstract}
The effects of thermal simulation on the short-term creep fracture of modified 91 (mod. 91) weld metal (WM) were evaluated at elevated temperature. The reheated zones in the WM during multiple passes were simulated by an infrared heater. The simulated WM specimens after post-weld tempering at $1023 \mathrm{~K} / 2 \mathrm{~h}$ were loaded with dead weight either at $903 \mathrm{~K} / 120 \mathrm{MPa}$ or $933 \mathrm{~K} / 80 \mathrm{MPa}$. In this work, the simulated WM specimens after tempering were loaded either at 903 and $933 \mathrm{~K}$ during the tests. The loss in creep lives of various specimens at elevated temperature was determined accordingly and further compared with the Gr. 91 steel base metals, which were normalized either at $1213 \mathrm{~K}$ or $1333 \mathrm{~K}$ and then tempered at $1033 \mathrm{~K}$ for $2 \mathrm{~h}$. The coarse, solidified structure of the WM had much better creep resistance than the base metal even that of the base metal normalized at $1333 \mathrm{~K}$. However, the imposed welding thermal cycles would cause a significant decrease in creep resistance of the WM. Creep lives were shortened obviously in the simulated WM samples, especially in the simulated sample that underwent partial transformation. The combination of a fine-grained structure and soft ferrite present in the simulated WM was responsible for their huge decline in creep resistance, as compared with the WM in the as-tempered condition.
\end{abstract}

Keywords: mod. 91 weld metal; thermal simulation; creep rupture; post-weld tempering

\section{Introduction}

Mod. 9Cr-1Mo steel is also known as Gr. 91 steel, which is used for the construction of superheaters in fossil power plants. Gr. 91 steel has good high temperature strength, low thermal expansion, and acceptable oxidation resistance [1]. P91 steel welds have low sensitivity to solidification cracking and are resistant to reheat cracking [2]. To improve the weld toughness, Gr. 91 steel welds need to be tempered at sufficient high temperature after welding. [3-6]. Higher weld toughness can be obtained by increasing the tempering temperature or prolonging the tempering period $[4,5]$. The tempering temperature of the Gr. 91 steel weld is reported to have greater influence on its hardness than does the holding time [4]. Post-weld heating is applied immediately after welding in order to prevent cold cracking and reduce the magnitude of residual stress of the weld. Post-weld heat treatment (PWHT) or post-weld tempering can obviously increase the toughness and completely remove the residual stress of the weld. Post-weld heating at $553 \mathrm{~K}$ for $40 \mathrm{~min}$ before the post-weld heat treatment (PWHT) is able to further increase the impact toughness of P91 weld metal (WM) [6]. Increasing the PWHT 
temperature from 993 to $1033 \mathrm{~K} / 1 \mathrm{~h}$ causes a systematic coarsening of precipitates but decrease in precipitate density, which result in a gradual decrease in both the yield and tensile strength of modified 91 steel welds [7]. The poor impact toughness of the as-welded (AW) heat-affected zone (HAZ) of a P91 weld can be upgraded by increasing the time for PWHT at $1033 \mathrm{~K}$ [8]. With the increase of $\mathrm{Nb}$ and V contents of the P91 WM, the increased precipitates cause a decline in impact toughness [9]. The toughness of coarse-grained HAZ (CGHAZ) increases slowly with increasing PWHT temperature and remains low until $1003 \mathrm{~K}$ [10]. It is reported that the presence of $\delta$ ferrite in the modified 91 (mod. 91) WM is harmful to its ductility and toughness [5]. Moreover, higher $\mathrm{Mn}+\mathrm{Ni}$ content in the WM will further lower the applicable tempering temperature, resulting in lower impact toughness after tempering [11].

A typical weld comprises of several different zones, including the WM, HAZ, and base metal (BM). Moreover, the HAZ can be further divided into the coarse-grained HAZ (CGHAZ), fine-grained HAZ (FGHAZ), intercritical heat-affected zone (ICHAZ) or partial transformation (PT) zone, and short-time over-tempering (STOT) zone, depending on the peak temperature of the specified zone. The ICHAZ or partial transformation (PT) HAZ experiences a peak temperature between $\mathrm{A}_{\mathrm{C} 1}$ and $\mathrm{A}_{\mathrm{C} 3}$, which leads to partial transformation or incomplete austenite formation therein. Heating the Gr. 91 steel just below $\mathrm{A}_{\mathrm{C} 1}$ temperature will lead to over-tempering $(\mathrm{OT})$, which causes the excessive annihilation of dislocations, break-down of lath structure, the polygonization, carbide-spherodizing and coarsening effects. Creep fracture of the advanced 9-12 Cr ferritic steel welds after long period operation at elevated temperature is named as Type IV cracking [12-16]. The ICHAZ, which is heated to below the $\mathrm{A}_{\mathrm{C} 3}$ temperature, has the lowest creep strength and is the most likely of the distinct zones of a P91 steel weld to fracture [17-20]. Creep voids formed in the HAZ result in the premature failure of the Gr. 91 steel weld [18].

In prior works, it has been observed that the normalizing temperature and imposed thermal cycles play important roles in the creep resistance of Gr. 91 and Gr. 92 steel welds [21,22]. The tensile strength of Gr. 91 steel in the normalized and tempered condition increases with increasing the solution temperature [17]. Moreover, increasing the normalizing temperature of Gr. 91 [21,23] and Gr. 92 [22] steels is beneficial to increase the resistance to creep fracture. The creep resistance of Gr.91 WM in this work was compared with the Gr.91 base metal [21] under the same testing condition. The WM normally consists of much coarser solidified microstructures than the granular base metal. The presence of soft ferrite in the mod. $91 \mathrm{WM}$ is expected to degrade its creep strength [24]. For a 9Cr-1Mo steel weld produced in multiple passes, the prior weld bead will be reheated by the subsequent beads, causing modification of the primary solidification structure [25].

The present work represents the results of the investigation of microstructural evolution of the mod. $91 \mathrm{WM}$ when thermal cycles were applied for a multi-pass weld. The microstructures of the reheated WM were examined and the microstructures before and after infrared simulation were inspected. Moreover, the influence of thermal simulation on the short-term creep fracture of the mod. $91 \mathrm{WM}$ was studied, and compared with the normalized and tempered base metal. The microstructures and fracture characteristics of the mod. $91 \mathrm{WM}$ were inspected by using a scanning electron microscope (SEM). Grain sizes and grain boundary characteristics of the WM were identified by electron backscatter diffraction (EBSD). Detailed microstructures were observed with a transmission electron microscope (TEM).

\section{Materials and Methods}

The chemical compositions (in wt.\%) of the Gr. 91 steel plate, T91 steel tube and the mod. $91 \mathrm{WM}$ are listed in Table 1. A butt joint of steel tube with $50 \mathrm{~mm}$ in diameter and $9.6 \mathrm{~mm}$ in wall thickness and a butt joint of steel plate with $12 \mathrm{~mm}$ in thickness were welded by using tungsten-inert-gas arc welding process in multiple passes, respectively. Figure 1 shows the joint geometries of two butt welds and the creep samples cut from the completed welds. The WM sample in the as-welded (AW) condition was named the $\mathrm{W}$ sample. The $\mathrm{W}$ sample subjected to post-weld tempering at $1023 \mathrm{~K} / 2 \mathrm{~h}$ was called 
the WP (WM in post-weld tempered condition) sample. A dilatometer was applied to measure the transformation temperatures of the WM, which were compared to the steel plate [26] and tube [21]. To determine the $A_{C 1}, A_{C 3}, M_{S}$, and $M_{f}$ temperatures (Table 2), the tested samples cut from the WM were heated to $1273 \mathrm{~K}$ at distinct heating rates, then cooled down to room temperature by Ar gas at different cooling rates.

Table 1. The chemical composition (in wt.\%) of Gr. 91 steel plate, tube, and weld metal.

\begin{tabular}{ccccccccccccccc}
\hline Materials & $\mathbf{C}$ & $\mathbf{M n}$ & $\mathbf{P}$ & $\mathbf{S}$ & $\mathbf{S i}$ & $\mathbf{C r}$ & $\mathbf{M o}$ & $\mathbf{V}$ & $\mathbf{N b}$ & $\mathbf{N}$ & $\mathbf{N i}$ & $\mathbf{A l}$ & $\mathbf{T i}$ & $\mathbf{F e}$ \\
\hline Steel plate & 0.10 & 0.36 & 0.017 & 0.004 & 0.39 & 8.78 & 0.94 & 0.20 & 0.07 & 0.040 & 0.12 & 0.004 & 0.002 & bal. \\
\hline Steel tube & 0.106 & 0.37 & 0.01 & 0.004 & 0.35 & 8.66 & 0.95 & 0.23 & 0.07 & 0.040 & 0.11 & 0.012 & 0.007 & bal. \\
\hline Weld metal & 0.08 & 0.72 & 0.012 & 0.002 & 0.19 & 8.95 & 0.81 & 0.17 & 0.12 & 0.040 & 0.47 & 0.001 & 0.0002 & bal. \\
\hline
\end{tabular}

(a)

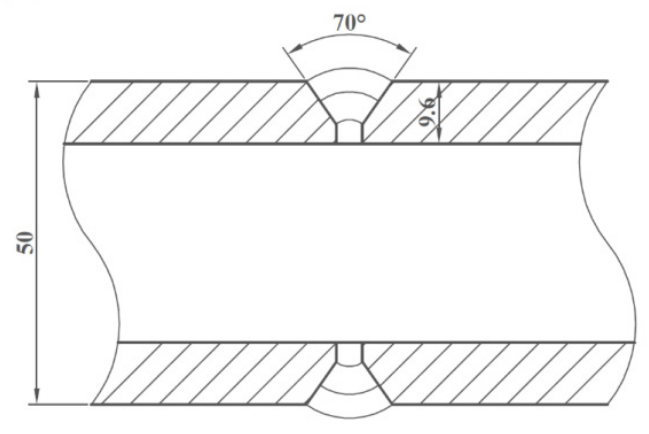

(b)
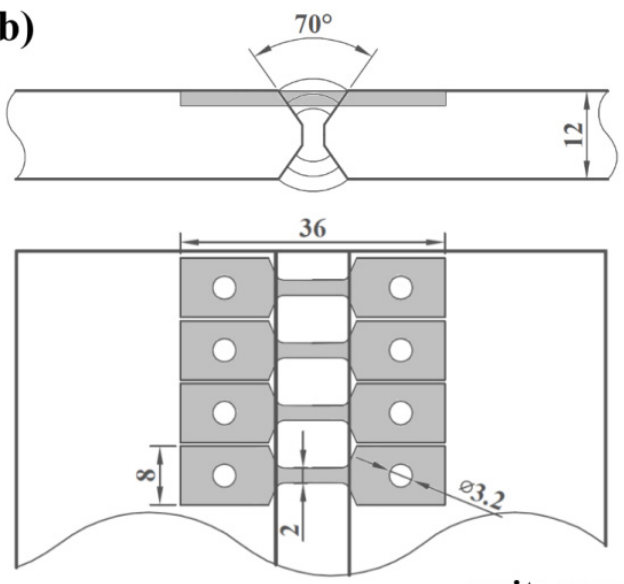

unit: mm

Figure 1. Schematic diagram showing the joint geometries of two butt welds: (a) T91 tube and (b) Gr. 91 plate and the creep samples cut from the completed welds.

Table 2. The transformation temperatures of Gr. 91 weld metal (WM) determined by a dilatometer at specific heating/cooling rates.

\begin{tabular}{ccccccccc}
\hline & Rates (K/s) & \multicolumn{4}{c}{ Heating Rate } & \multicolumn{5}{c}{ Cooling Rate } \\
\cline { 3 - 10 } Temperature (K) & 5 & 15 & 30 & 45 & 5 & 15 & 30 & 45 \\
\hline $\mathrm{Ac}_{1}$ & 1104 & 1115 & 1121 & 1123 & & & - \\
$\mathrm{Ac}_{3}$ & 1133 & 1158 & 1166 & 1168 & & & & \\
\hline $\mathrm{M}_{\mathrm{S}}$ & & & - & & 654 & 653 & 651 & 642 \\
$\mathrm{M}_{\mathrm{f}}$ & & & & & 592 & 590 & 553 & 533 \\
\hline
\end{tabular}

The deposited weld bead underwent phase transformation when subsequent weld beads were applied. For comparison with prior works studying the induced phase transformation in the HAZ of a Gr. 91 weld, the WP samples were heated using an infrared heating system to a specific temperature to generate over-tempered (OT) or partially-transformed (PT) microstructures, which were produced by heating the samples to $1073 \mathrm{~K}\left(800{ }^{\circ} \mathrm{C}\right)$ or $1133 \mathrm{~K}\left(860{ }^{\circ} \mathrm{C}\right)$ for 1 min at a heating rate of $15 \mathrm{~K} / \mathrm{s}$, followed by Ar-cooling to room temperature. Simulated samples were nominated as WP-800 or WP-860, depending on the peak temperature. After infrared heat-treatment, some of the simulated samples were tempered at $1023 \mathrm{~K} / 2 \mathrm{~h}$. In such case, the letter P was attached to the designated sample, e.g., WP-800P meant the tempered WP-800 sample.

A micro-Vickers hardness tester (MVK-G1500, Mitutoyo, Kawasaki, Japan) applied 300 gf loading for $15 \mathrm{~s}$ to determine the WM hardness in the AW or tempered conditions. The hardnesses of simulated samples in Table 3 were the average of 8 measurements. To understand the microstructural evolution of 
the WM and its effect on the creep failure of simulated specimens, simulated samples after tempering were loaded with dead weight either at the $903 \mathrm{~K} / 120 \mathrm{MPa}$ or $933 \mathrm{~K} / 80 \mathrm{MPa}$. The creep tests were terminated if the tested specimens did not fracture after loading for $3000 \mathrm{~h}$. The microstructures of investigated specimens were observed with an optical microscope (BX51, Olympus, Tokyo, Japan) and an SEM (3400, Hitachi, Tokyo, Japan). Moreover, the investigated samples were inspected with an SEM equipped with electron backscatter diffraction (EBSD, Oxford Instruments, Abingdon, UK) to display their grain sizes and grain boundary characteristics. Transmission electron microscope (TEM, 2000EX, JEOL, Tokyo, Japan) was used to examine the complex microstructures of the investigated samples.

Table 3. The hardness of the Gr. 91 WM samples in different conditions.

\begin{tabular}{ccccccc}
\hline Sample & W & WP & WP-800 & WP-860 & WP-800P & WP-860P \\
\hline Hardness (HV) & 400 & 240 & 230 & 361 & 229 & 221 \\
\hline
\end{tabular}

\section{Results}

\subsection{Measurements of Transformation Temperatures}

As listed in Table 1, the steel plate and tube had quite similar chemical compositions. By contrast, the filler wire contained a little less $\mathrm{C}$ but slightly more $\mathrm{Mn}$ and Ni content than did the steel plate and tube. It is reported that the total $\mathrm{Mn}+\mathrm{Ni}$ content should be kept below $1.5 \%$ to prevent a lower $\mathrm{A}_{\mathrm{C} 1}$ temperature [11], which would prevent tempering of the weld at a sufficiently high temperature to improve its toughness. The transformation temperatures of the WM measured by a dilatometer at different heating/cooling rates are listed in Table 2. It indicated that the $A_{C 1}$ and $A_{C 3}$ temperatures slightly increased with increasing heating rates. In contrast, the $\mathrm{M}_{\mathrm{S}}$ and $\mathrm{M}_{\mathrm{f}}$ temperatures decreased with increasing cooling rates. As compared with the steel plate [26], the $A_{C 1}$ and $A_{C 3}$ temperatures of the WM were about $30 \mathrm{~K}$ lower than those of the steel plate, respectively. The results indicated that the WM tended to undergo phase transformation at a lower temperature relative to the BM if a thermal cycle was applied. Such a difference in transformation temperatures between the WM and BM could be attributed to the compositional effect. Based on alloy design, the higher $\mathrm{Mn}+\mathrm{Ni}$ content in the WM lowered the transformation temperatures, and the lower C content in the WM tended to decrease its as-welded hardness.

\subsection{Microhardness of Distinct Zones in a Weld}

Figure 2 displays the macroscopic appearance of a T91 butt weld in cross-sectional view (Figure 2a) and microhardness profiles from the centerline of the WM across the HAZ to the BM in the AW or tempered conditions (Figure 2b). It revealed that a fluctuation in WM hardness from HV 355 to HV 380 was obtained in the AW condition. Peak hardness above HV400 was noted in the HAZ adjacent to the fusion boundary, as there was a sharp decrease in hardness away from the fusion zone in the AW condition. After tempering at $1003 \mathrm{~K}$ or $1023 \mathrm{~K} / 2 \mathrm{~h}$, the differences in hardness among the WM, HAZ, and BM were reduced obviously. The WM and HAZ hardnesses decreased to below HV 275 after tempering. In the as-welded state, the soft zone was found within a very narrow width ahead of the BM, and it became wider after tempering. Increasing the tempering temperature up to $1023 \mathrm{~K}$, the hardness of the WM and HAZ further decreased. Regardless of tempering temperature, the difference in hardness in the HAZ between two tempered samples was minor. This minor difference in hardness implied that a uniform hardness distribution in a Gr. 91 weld could be obtained if post-weld tempering at/above $1003 \mathrm{~K}$ was performed. 

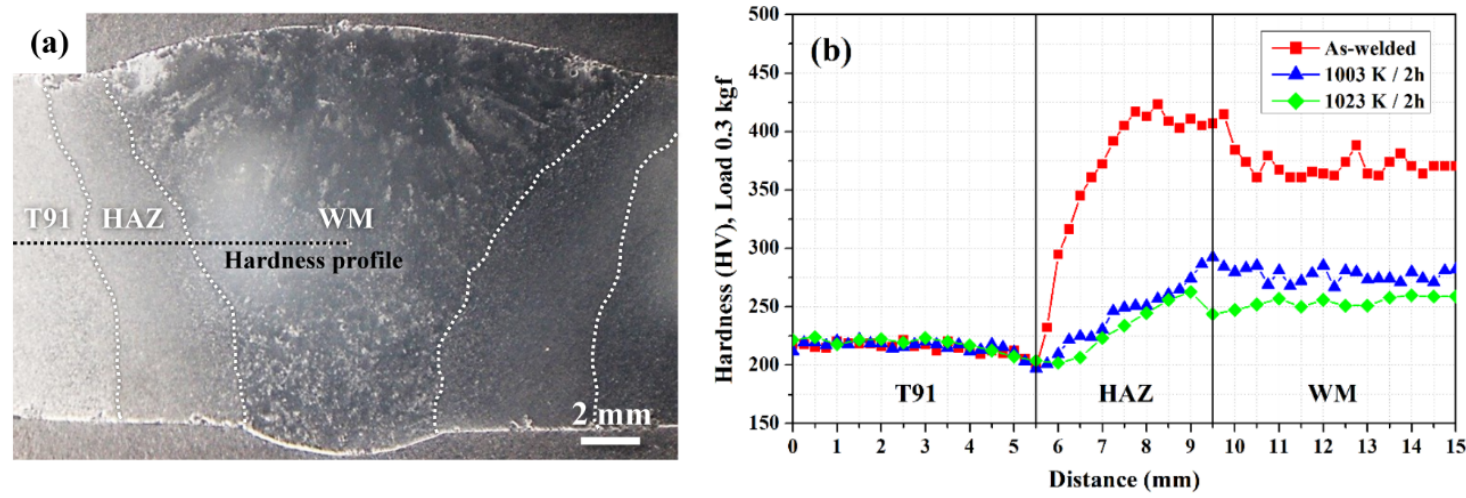

Figure 2. (a) Macroscopic appearance of a T91 weld in cross-sectional view, (b) microhardness profiles from the centerline of the WM across the heat-affected zone (HAZ) to the base metal (BM) in the as-welded and tempered conditions.

Figure 3 shows the cross-sectional view of the butt-welded plate after multiple-pass welding (Figure 3a) and the hardness distribution in the vertical direction from the center to the weld surface (Figure $3 b$ ). To lower the weld distortion, a double V groove was selected for butt-welding the $12 \mathrm{~mm}$ plate, as shown in Figure $1 \mathrm{~b}$. The results indicated that the WM hardness was in the range of HV 420 to HV 360 in the AW condition. The deviation in WM hardness in the AW condition could be attributed to the imposed thermal cycles that produced a short-time tempering effect during multiple-pass welding. After tempering at $1023 \mathrm{~K} / 2 \mathrm{~h}$, the peak WM hardness decreased obviously to below HV 245, which was still higher than that of the BM.
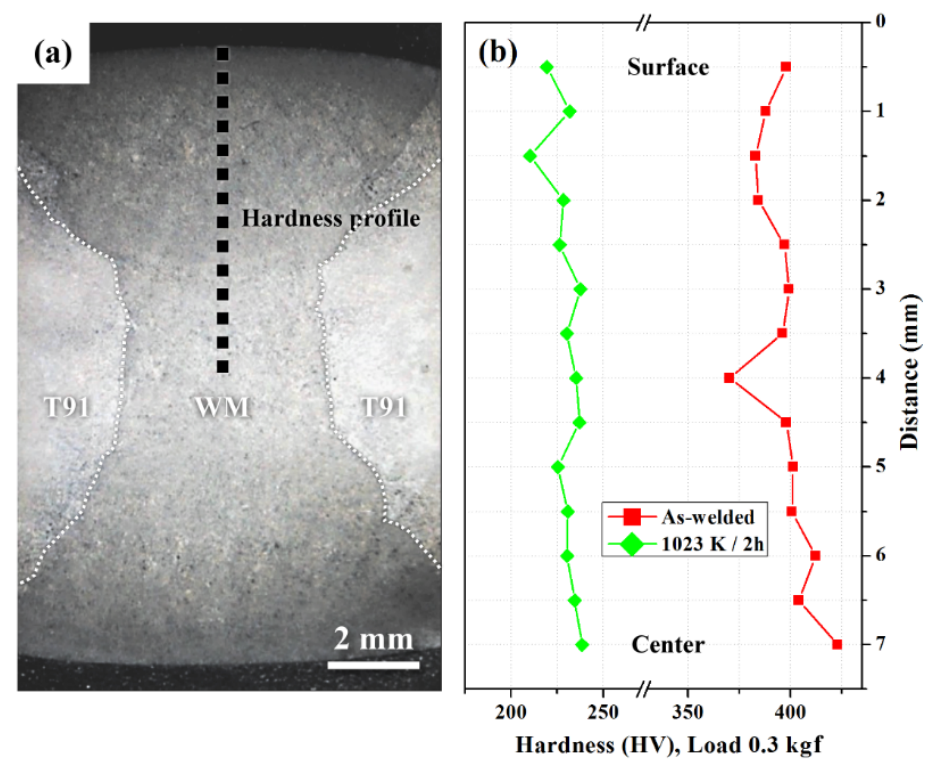

Figure 3. (a) The cross-sectional view of the butt-welded plate after multiple-pass welding and (b) the hardness distribution in the vertical direction from the weld surface to the center.

The $\mathrm{A}_{\mathrm{C} 1}$ and $\mathrm{A}_{\mathrm{C} 3}$ temperatures of the $\mathrm{WM}$ tested at the heating rate of $15 \mathrm{~K} / \mathrm{s}$, listed in Table 2 were 1115 and $1158 \mathrm{~K}$, respectively. After tempering at $1023 \mathrm{~K}$, the WM samples were heated by infrared heater to 1073 or $1133 \mathrm{~K}$ to simulate the reheated microstructures in a weld of multiple passes; the peak temperature would cause over-tempering or incomplete austenite transformation. Table 3 lists the microhardness of various samples with or without post-weld tempering at $1023 \mathrm{~K} / 2 \mathrm{~h}$. The as-welded WM (W sample) had a hardness of about HV 400, and it decreased to HV 240 after tempering (WP sample). The specimen heated by infrared to $1073 \mathrm{~K}$ (WP-800 sample) had a hardness 
of HV 230, which was a little softer than the WP sample. Moreover, the WP-800 and WP-800P samples had nearly the same hardness. For the sample heated to $1133 \mathrm{~K}$ by infrared furnace, the WP-860 sample showed moderate hardening, and the hardness was about HV 360. By contrast, the hardness of the WP-860P sample was a little lower than that of other samples in the same tempered condition.

\subsection{Microstructural Observations}

Figure 4 shows the microstructures of the WM in the AW and tempered conditions. In the AW condition, the SEM micrograph showed that the WM sample consisted of coarse martensite packets (Figure 4a). In the AW condition, TEM micrograph revealed a fine lath structure without carbide precipitates in the WM (Figure 4b). After tempering, the grain boundaries and lath boundaries of the WP sample were decorated with fine precipitates (Figure 4c). TEM micrograph presented that the elongated and spherodized $\mathrm{M}_{23} \mathrm{C}_{6}$ carbides were present predominantly along the lath boundaries of the tempered WM (Figure 4d). Post-weld tempering at/above $1003 \mathrm{~K} / 2 \mathrm{~h}$ causes the occurrence of recovery and recrystallization, which leads to fragmentation of martensite laths and the formation of equiaxed grains in a Gr. 91 WM [4]. Increasing the tempering temperature from 1003 to $1033 \mathrm{~K}$ results in more intense recovery and recrystallization of WM [4].
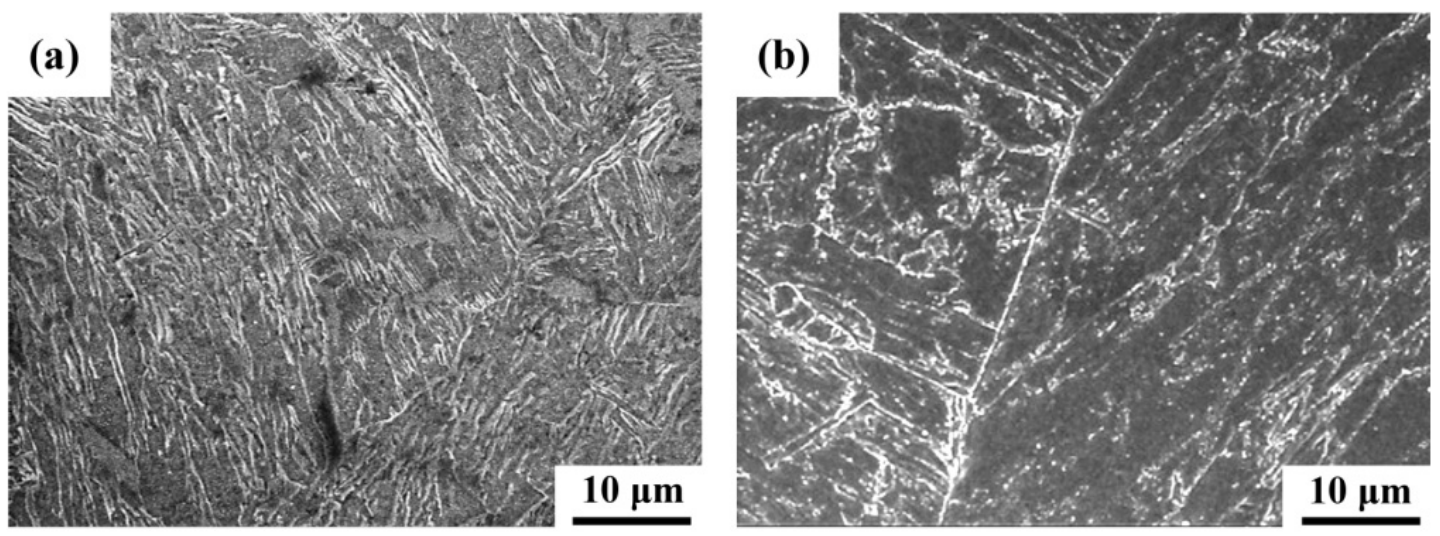

(c)
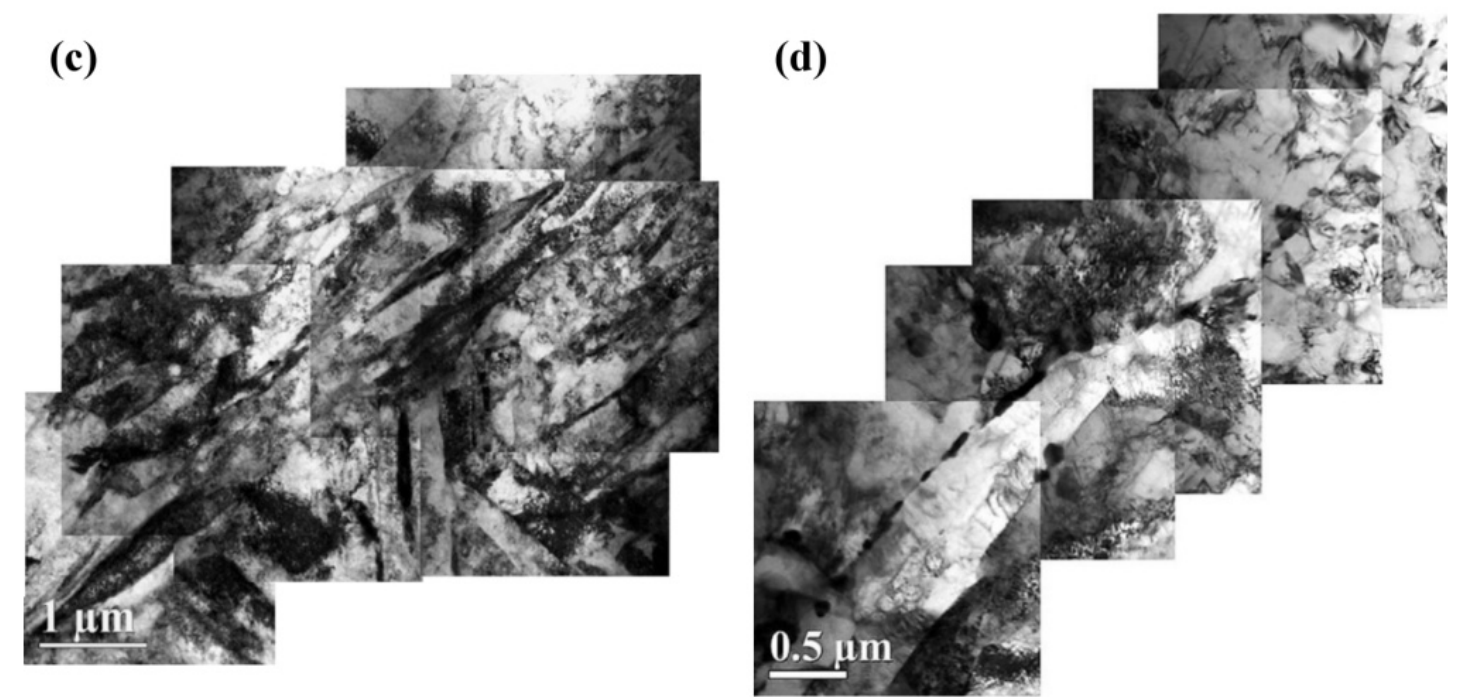

Figure 4. The microstructures of the WM in the as-welded (a-c) and tempered (b-d) conditions. $(\mathbf{a}, \mathbf{b})$ scanning electron microscope (SEM) micrographs; (c,d) transmission electron microscope (TEM) micrographs.

The $\delta$ ferrite was expected to form in the WM during the initial stage of solidification. Rapid cooling after welding inhibits the complete transformation of $\delta$ ferrite to $\gamma$; thus, $\delta$ ferrite is retained in 
the WM after cooling to room temperature. To distinguish the different microstructures formed in the WM, micro-hardness indentation loaded under $50 \mathrm{gf}$ was performed to reveal the discrepancies in hardness between the dark patches (ferrite) and lath structure (martensite). The high hardness of the as-welded WM was the result of formation of fresh martensite. The ferrite would be much softer than the untempered martensite in the as-welded WM. As shown in Figure 5, the dark zone had much lower hardness than the surrounding lath matrix (Figure 5a). The difference in hardness between the ferrite and tempered martensite was found to decrease obviously in the WP sample (Figure 5b). However, the ferrite was still the weak zone, as compared with the tempered martensite. It was noticed that a coarse white zone was more likely to be observed in the WP-800P and WP-860P samples than that in the WP sample (Figure 5c,d). Post-weld tempering at $1023 \mathrm{~K} / 2 \mathrm{~h}$ could effectively reduce the dislocation density of the martensite lath and assist the combination of fine laths into a coarse one, which enhances the formation of coarse ferrite. The formation of coarse ferrite in those simulated samples after tempering was expected to degrade the creep resistance of the Gr. 91 steel weld.
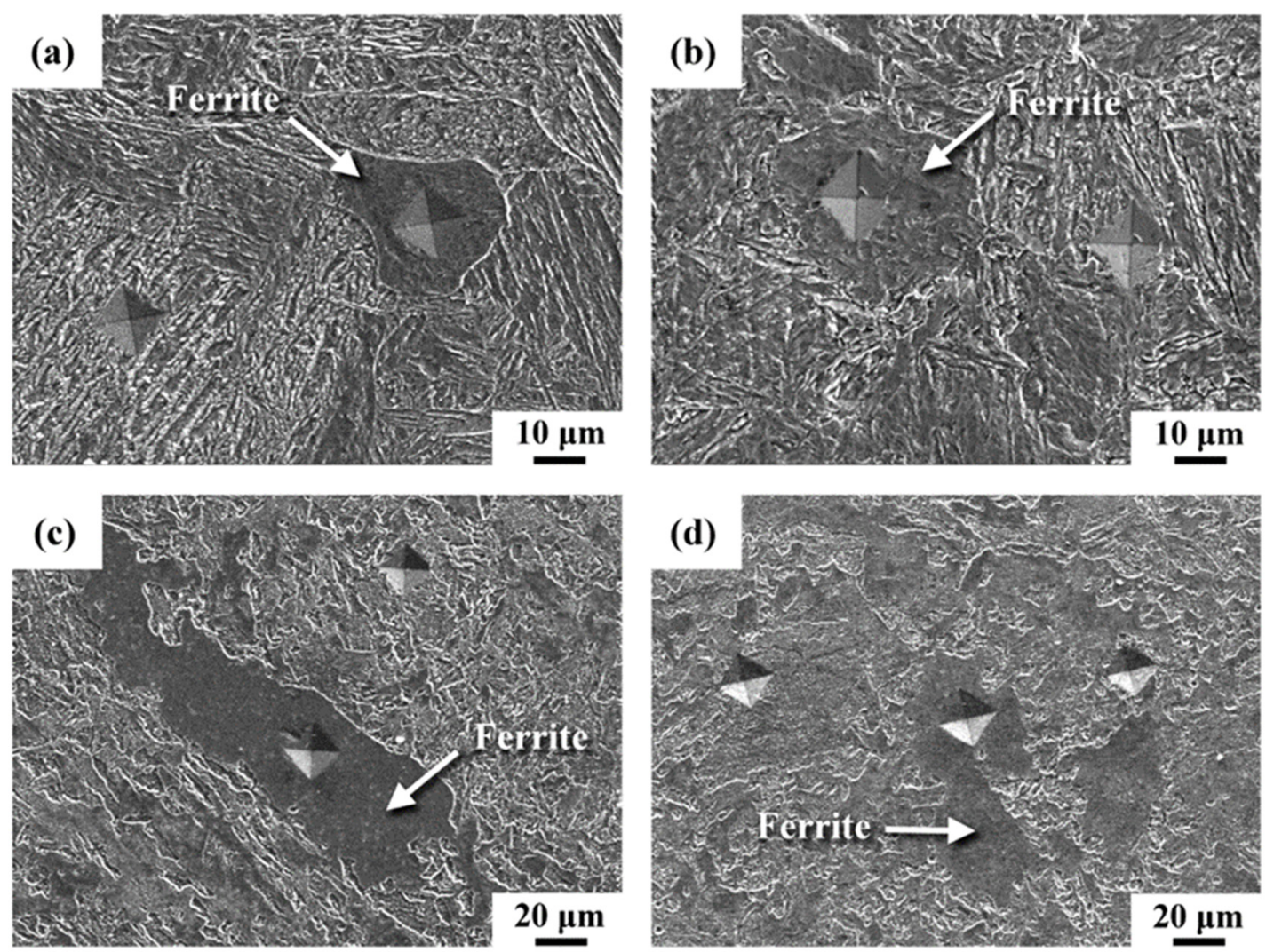

Figure 5. The hardness indentation on the ferrite and lath martensite in distinct samples: (a) W, (b) WP, (c) WP-800P and (d) WP-860P specimens.

Figure 6 presents TEM micrographs of the WP-800P and WP-860P samples. The microstructure of the WP-800P sample consisted of lath martensite with $\mathrm{M}_{23} \mathrm{C}_{6}$ carbides present mainly along the lath boundaries (Figure 6a). In addition, uneven $\mathrm{M}_{23} \mathrm{C}_{6}$ carbide distribution and a few lath boundaries with greater amounts of aggregated $\mathrm{M}_{23} \mathrm{C}_{6}$ carbides were observed. Moreover, several small carbides could coalesce into very coarse carbides (Figure 6b). In the WP-860P sample (Figure 6c), the lath morphology remained but degraded. Furthermore, numerous carbides precipitated along the boundaries and within ferrite subgrains, which could be attributed to the coalescence of fine laths or nucleated fine ferrite during the imposed thermal treatments (Figure 6d). 

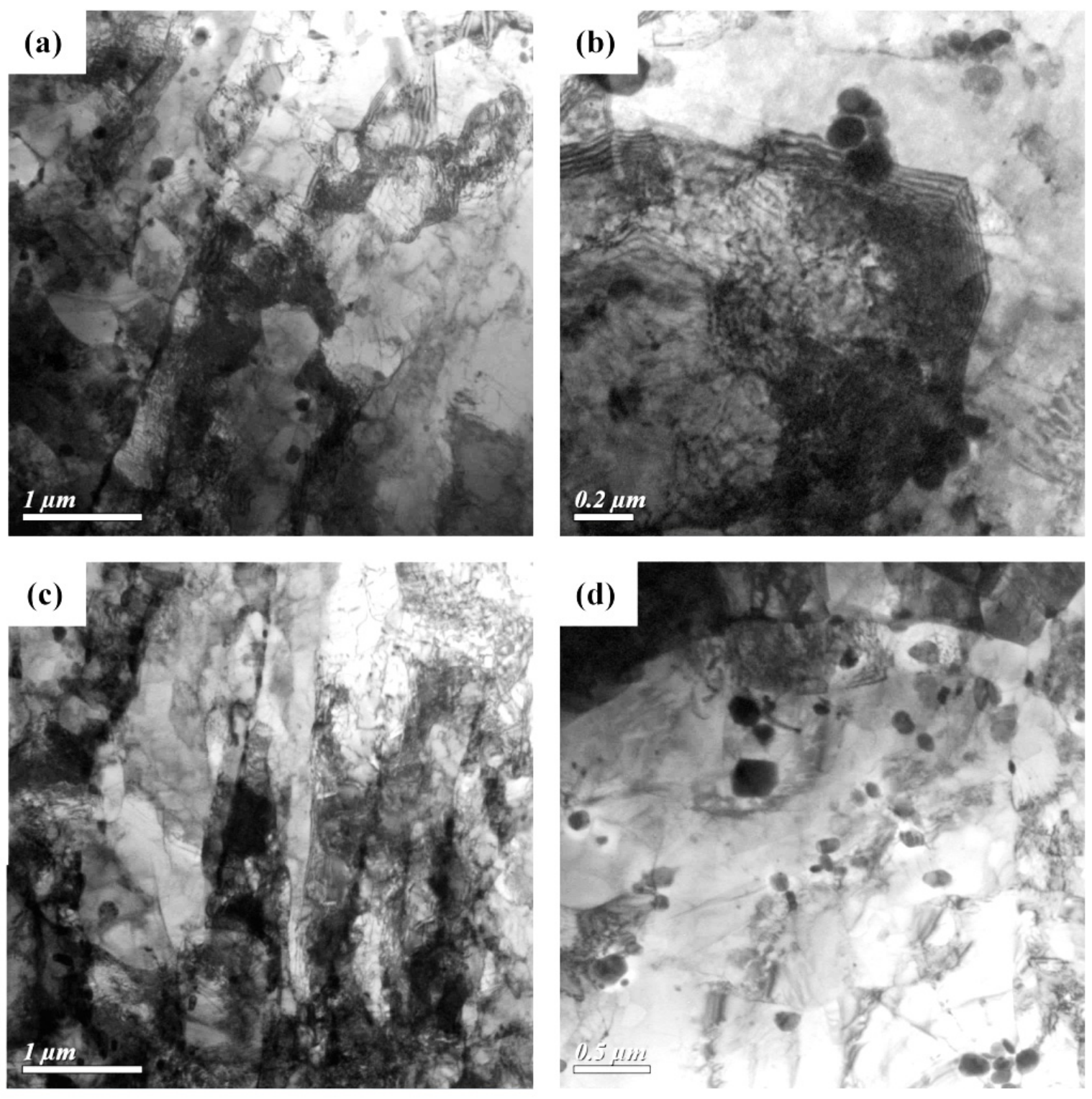

Figure 6. TEM micrographs of the (a,b) WP-800P and (c,d) WP-860P samples.

\subsection{Inverse Pole Figures}

Figure 7 is the inverse pole figures (IPFs) showing the individual grain orientations in various colors of the tested samples. An obvious change in color represents a large difference in grain orientation. Martensite packets oriented in the same direction are of the same color; the lath packets of different colors are aligned in various orientations. The results indicated that the solidified structures and martensite packets of the W and WP specimens were similar (Figure 7a,b), showing very coarse structures and packet sizes. The fine laths in the $\mathrm{W}$ sample tended to combine into coarse laths in the WP sample. For the WP sample subjected to short-time over-tempering by infrared heating, the microstructural features of the WP-800 sample (Figure 7c) were similar to those of the W and WP samples. It was noticed that the occurrence of polygonization in the WP-800 sample tended to divide the wide laths into parallel short and fine laths. Refined laths and oriented subgrains, which should belong to the same martensite packets, were easy to be observed in the WP-800P sample (Figure 7d). It was clear that post-weld tempering enhanced the degradation of the lath structure and assisted the polygonization process. Moreover, the WP-860 sample (Figure 7e) showed completely different 
microstructural features, as compared with the above-mentioned samples. Coarse martensite packets were not found in the WP-860 sample. The original coarse laths were replaced by small patches separated by sub-boundaries. After post-weld tempering, a fine-grained structure instead of the initially coarse grains/packets in the WP sample was seen in the WP-860P sample (Figure 7f). It was obvious that the welding thermal cycles induced great microstructural changes in the WM, particularly in the samples heated below the $\mathrm{A}_{\mathrm{C} 3}$ temperature. It seemed that post-weld tempering enhanced the formation of the fine-grained WP-800P and WP-860P samples.
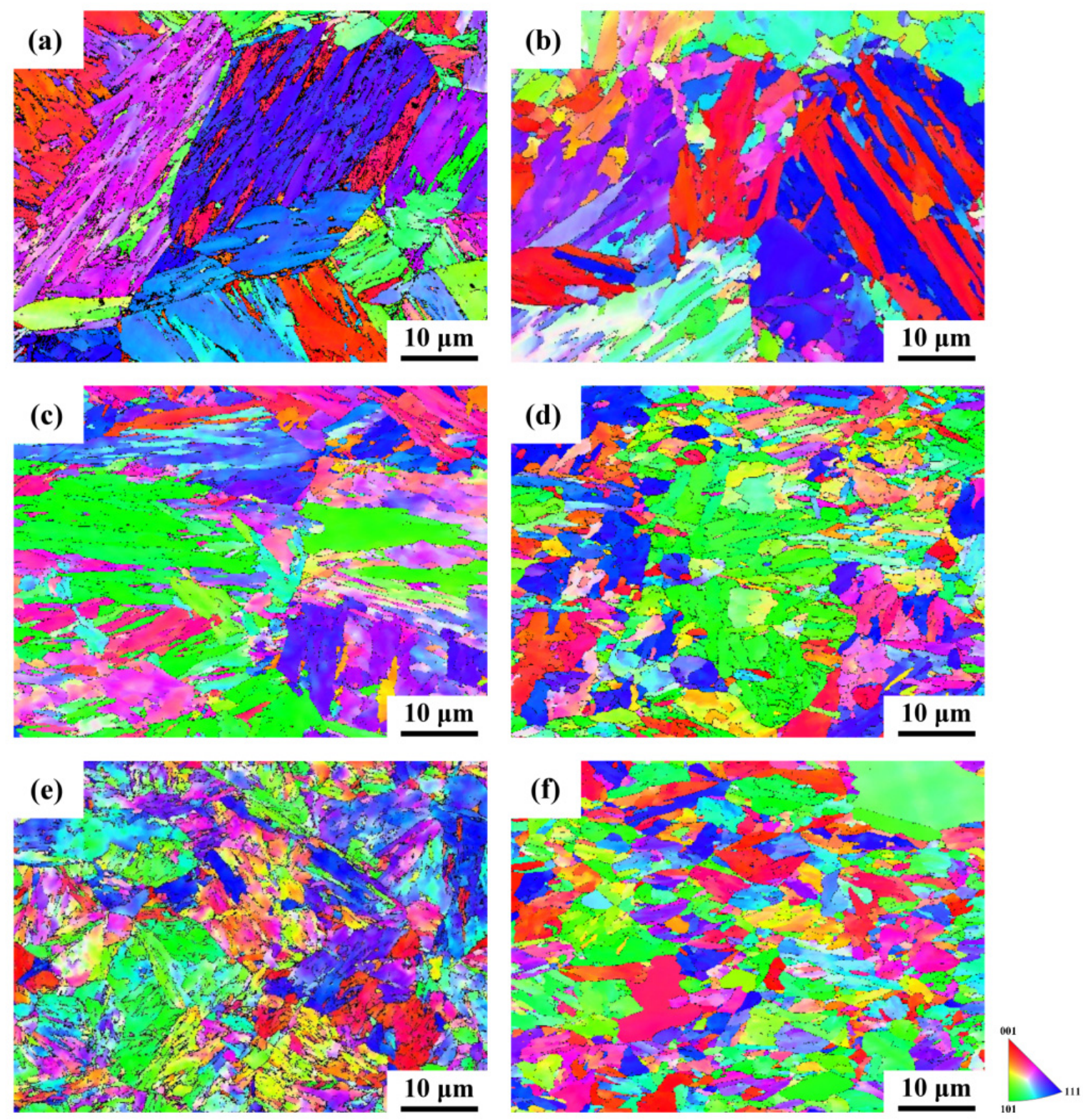

Figure 7. The inverse pole figures (IPFs) of the (a) W, (b) WP, (c) WP-800, (d) WP-800P, (e) WP-860 and (f) WP-860P specimens.

\subsection{Grain Boundary Characteristics}

Grain boundary maps showing the details of the $\gamma$ grain boundaries and sub-boundaries of tested samples are provided in Figure 8. Low-angle grain boundaries (LAGBs) include the lath and block/packet boundaries within the matrix, which have misorientations of $2-15^{\circ}$ and $50-60^{\circ}$ between adjacent grains. High-angle grain boundaries (HAGBs) are related with prior $\gamma$ grain boundaries and 
have misorientations of $15-50^{\circ}$. In this work, the LAGBs are indicated by red $\left(1-5^{\circ}\right)$ and green $\left(5-15^{\circ}\right)$ lines and HAGBs (15-62.5 $)$ are indicated by dark blue. The results indicated that the $W$ sample in the as-welded state consisted of a high density of LAGBs and few HAGBs (Figure 8a). The presence of HAGBs within the coarse grains was mainly associated with the discrepancies in orientation of the martensite packets, which could be confirmed by the IPF map shown in Figure 7a. It was seen that the density of the LAGBs decreased and the amount of the HAGBs increased in the tempered (WP) weld (Figure $8 b$ ) relative to the $\mathrm{W}$ sample (Figure $8 \mathrm{a}$ ). The reduction in the amount of LAGBs in the WP sample meant the annihilation of dislocations in the tempered martensite relative to the $\mathrm{W}$ sample. Moreover, fine grains were more likely to nucleate along the HAGBs of the WP sample.
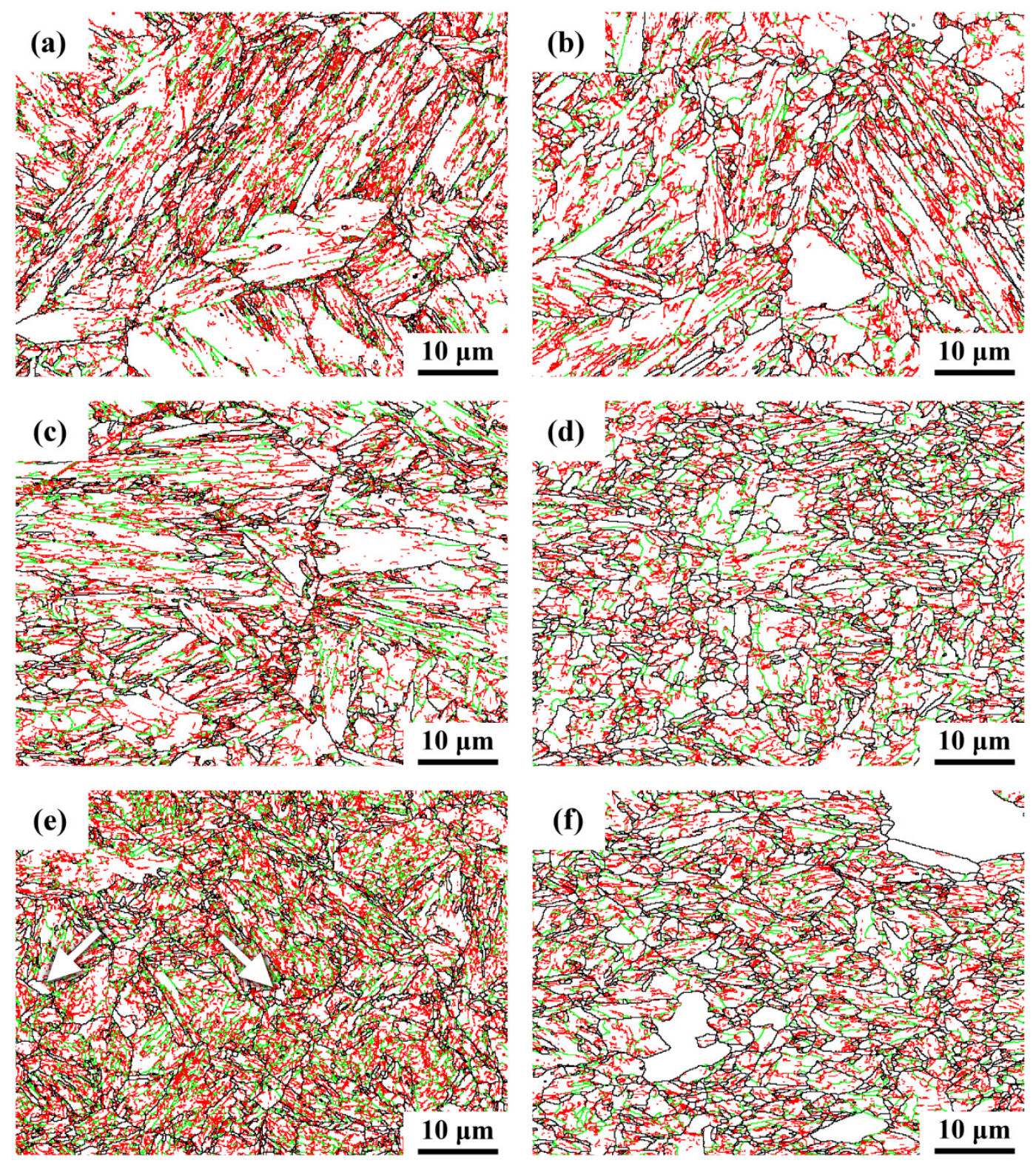

Figure 8. Grain boundary maps of the (a) W, (b) WP, (c) WP-800, (d) WP-800P, (e) WP-860 and (f) WP-860P specimens. ( $\left(1-5^{\circ}, \square: 5-15^{\circ}, \square\right.$ : $\left.15-62.5^{\circ}\right)$.

The grain boundary characteristics of the WP-800 and WP-800P specimens are displayed in Figure $8 \mathrm{c}$,d. As a whole, the amount of HAGBs in the WP-800 specimen (Figure 8c) was more or less similar to those in the W and WP samples, and the coarse-grained structure was retained in all 
three samples. However, more HAGBs were found in the WP-800P specimen than in the WP-800 one, which accounted for the refined grains of the former (Figure 8d). The results indicated that post-weld tempering enhanced the nucleation of fine grains in the STOT sample. For the samples heated in the two-phase region, the grain outlines of the HAGBs of the WP-860 sample (Figure 8e) were much finer and more irregular than those in other samples. The original coarse-grained structure present in the $\mathrm{W}$ and WP samples was completely absent from the WP-860 sample. Moreover, some small white patches without LAGBs (indicated by the arrows) were observed, and these could be related to the formation of ferrite subgrains. The grain boundary characteristics of the WP-860P sample (Figure 8f) were similar to those of the WP-860 one; both consisted of refined grains. It was seen that the white patches in the WP-860P sample were coarser and more numerous than those in the WP-860 one. Therefore, fine-grained structure and soft ferrite subgrains (white zones) would lead to lower the creep resistance of the WP-860P sample relative to the other samples.

\subsection{Short-Term Creep Tests}

For P91 steel in the first $3000 \mathrm{~h}$ of exposure at 600 or $650{ }^{\circ} \mathrm{C}$, a fast decrease in the dislocation density and an increase in the lath and $\mathrm{M}_{23} \mathrm{C}_{6}$ carbide sizes occur [27]. According to prior works [21,22], the results of short-term creep tests of simulated Gr. 91 and Gr. 92 steels reveal the same trend as the reported long term creep tests. In a prior work [21], the Gr. 91 steel tube was normalized either at 940 or $1060^{\circ} \mathrm{C}$ for $1 \mathrm{~h}$, followed by Ar-assisted cooling to room temperature then tempered at $760^{\circ} \mathrm{C}$ for $2 \mathrm{~h}$, which were nominated as the $940 \mathrm{NT}$ or $1060 \mathrm{NT}$ samples. Furthermore, the results of creep tests of the WM were compared with those of the 940NT or 1060NT samples [21]. Creep tests of specimens were carried out either at $903 \mathrm{~K} / 120 \mathrm{MPa}$ or $933 \mathrm{~K} / 80 \mathrm{MPa}$, shown in Figure 9. At least three tests were performed on given samples under a specific creep condition. The results of short-term creep tests could not be converted to long-term operation, but they are still able to reveal the mechanical properties of the tested samples at elevated temperature. The short-term creep tests were carried out to evaluate the effect of thermal cycles on the material properties at elevated temperature. The creep tests were terminated if the specimens did not fracture after loading for $3000 \mathrm{~h}$. The specimen elongation was also determined to show the creep resistance after creep fracture. Under constant load at elevated temperature, sustained loading may cause obvious high-temperature plastic deformation (high elongation) of the tested sample. If it occurs, it means the sample is weak and less resistant to external loading at elevated temperature. As compared with the Gr. 91 base metals, the WM sample (WP) was much more resistant to creep rupture than the two kinds of BM samples and did not fracture within the testing period at the $903 \mathrm{~K} / 120 \mathrm{MPa}$. It seemed that the coarse-grained structure of the WM conferred the creep resistance superior to that of the normalized and tempered BM. As indicated in Figure 9a, the stress-rupture lives of the WP samples decreased significantly if the thermal cycle was applied. The creep lives of the over-tempered (WP-800P) and partially transformed (WP-860P) samples were shortened obviously, particularly that of the WP-860P sample. Similar to the steel base metal undergoing partial transformation, the WP-860P sample had significantly inferior creep resistance relative to the WP sample. Creep rupture strength was not measure in this work. Under constant loading at elevated temperature, the occurrence of plastic deformation of the tested sample also implied the creep strength was low relative to the sample without deformation. Thus, the high elongation of those simulated samples with partially transformed microstructures was related to the inherent low creep strength. Regardless of testing conditions, all the simulated samples that underwent partial transformation were more prone to creep rupture in each group (Figure 9a,b). Moreover, all the evidence indicated that the imposed welding thermal cycles had a detrimental effect on the creep resistance of the advanced $9 \mathrm{Cr}$ steel welds. 

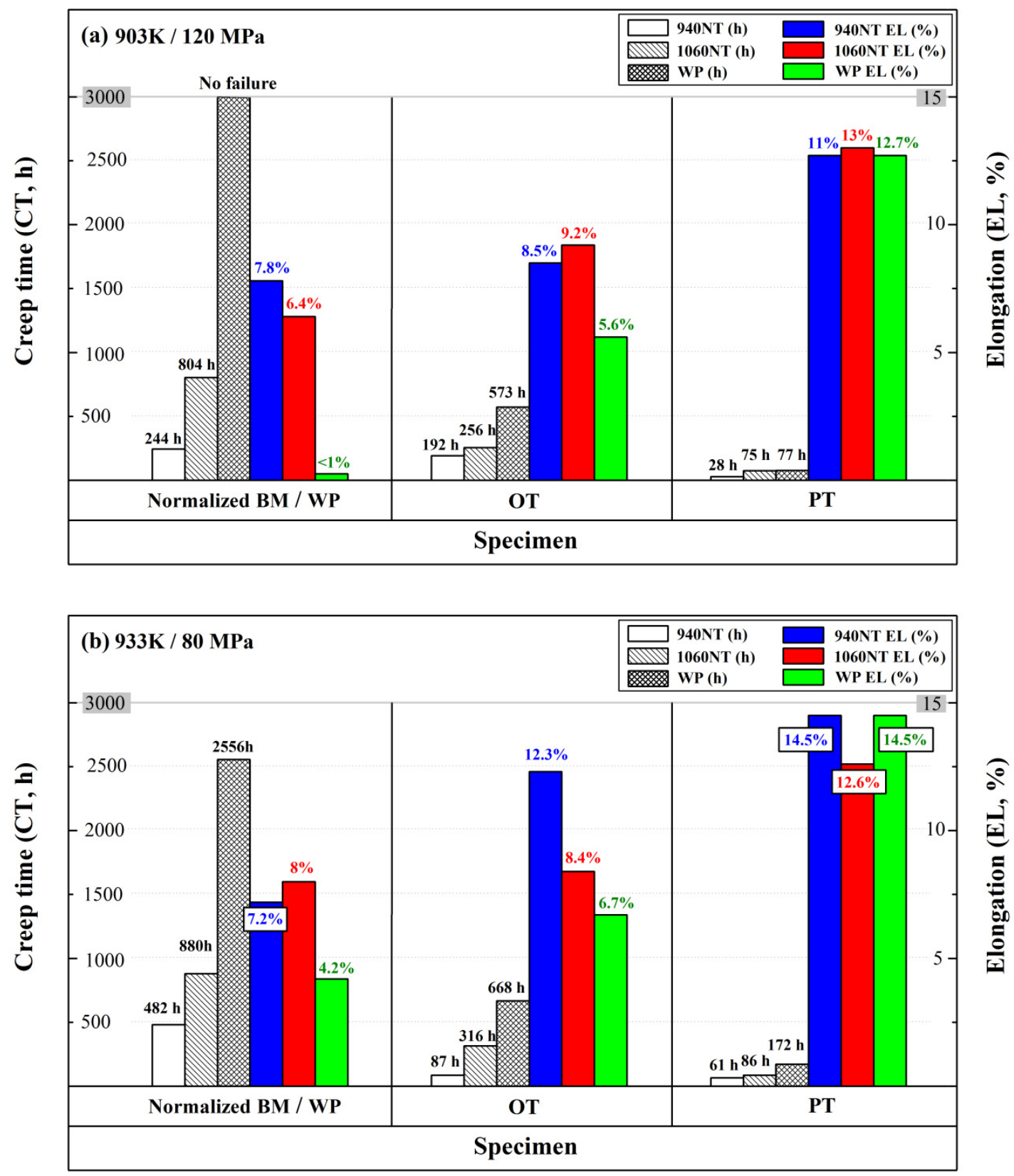

Figure 9. Short-term creep tests of specimens loaded under (a) $903 \mathrm{~K} / 120 \mathrm{MPa}$ and (b) $933 \mathrm{~K} / 80 \mathrm{MPa}$ conditions.

\subsection{Fracture Zone Examinations}

The IPF maps and the corresponding grain boundary maps around the creep fracture zones of the samples tested at the $903 \mathrm{~K} / 120 \mathrm{MPa}$ are displayed in Figure 10. The WP sample did not rupture during the testing interval at the $903 \mathrm{~K} / 120 \mathrm{MPa}$ and the average creep lives of the WP-800P and WP-860P samples were 573 and $77 \mathrm{~h}$, respectively. The grain orientations in the creep fracture zone of the two samples were more likely to align along the [001] direction. Straining the WP-800P sample at $903 \mathrm{~K}$ caused dynamic recrystallization, resulting in the formation of a fine-grained structure (indicated by the arrows) in comparison with the un-strained sample (Figure 10a,c). Furthermore, the WP-860P sample (Figures $7 \mathrm{f}$ and $8 \mathrm{f}$ ) consisted of refined grains and a high fraction of white patches. Those fine patches had fewer LAGBs (Figure 8f) and were related with the formation of ferrite subgrains. The fracture zone of the WP-860P sample displayed extensive formation of ferrite subgrains (Figure 10b,d), which could be attributed to the occurrence of dynamic recrystallization during creep-straining. 

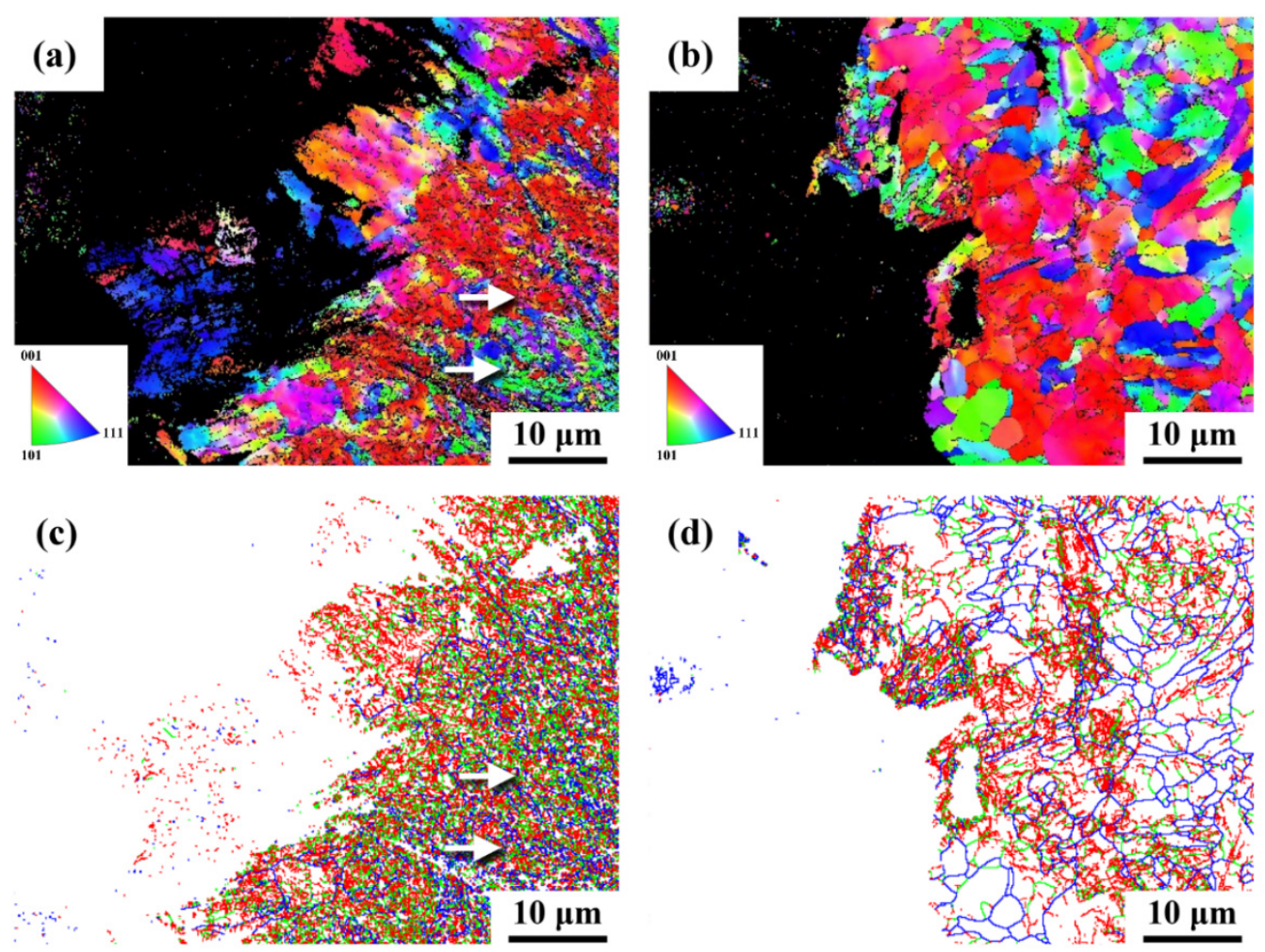

Figure 10. $(\mathbf{a}, \mathbf{b})$ The inverse pole figures, $(\mathbf{c}, \mathbf{d})$ grain boundary maps of the fracture zone for the $(\mathbf{a}, \mathbf{c})$ WP-800P specimen and (b,d) WP-860P specimen tested at $903 \mathrm{~K} / 120 \mathrm{MPa}$. $1-5^{\circ}$ $: 5-15^{\circ}$ - $\left.15-62.5^{\circ}\right)$.

Under the $933 \mathrm{~K} / 80 \mathrm{MPa}$ condition, the average creep lives of the WP, WP-800P, and WP-860P samples were 2556, 668, and $172 \mathrm{~h}$, respectively (Figure 9b). Overall, the WP and WP-800P samples somehow retained a coarse-grained structure as compared with the WP-860P sample (Figure 11). Moreover, preferred textures in the fracture zone were less likely to be found in those three samples tested at the $933 \mathrm{~K} / 80 \mathrm{MPa}$. After $2556 \mathrm{~h}$ of straining, white zones were rare in the fracture zone of the WP sample (Figure 11b) but common in the WP-800P (Figure 11d) and WP-860P (Figure 11f) samples. The results also indicated that the WP sample still possessed a high density of LAGBs. In contrast, the lack of LAGBs in the WP-800P and WP-860P samples implied the occurrence of dynamic recrystallization during creep-loading. The original lath structures in the un-crept WP-800P and WP-860P samples were replaced by numerous ferrite subgrains in the fracture zone of the crept samples. 

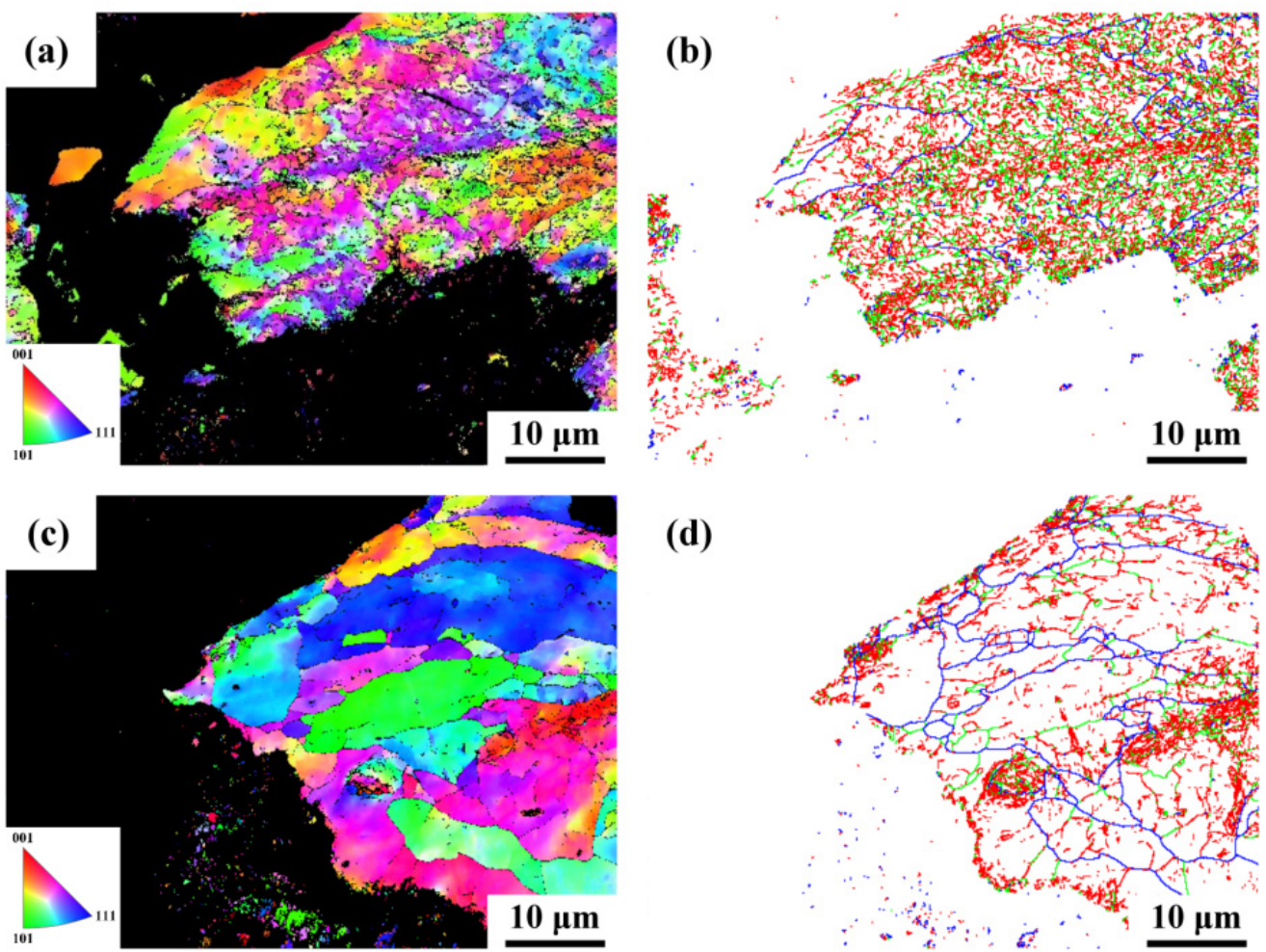

(d)
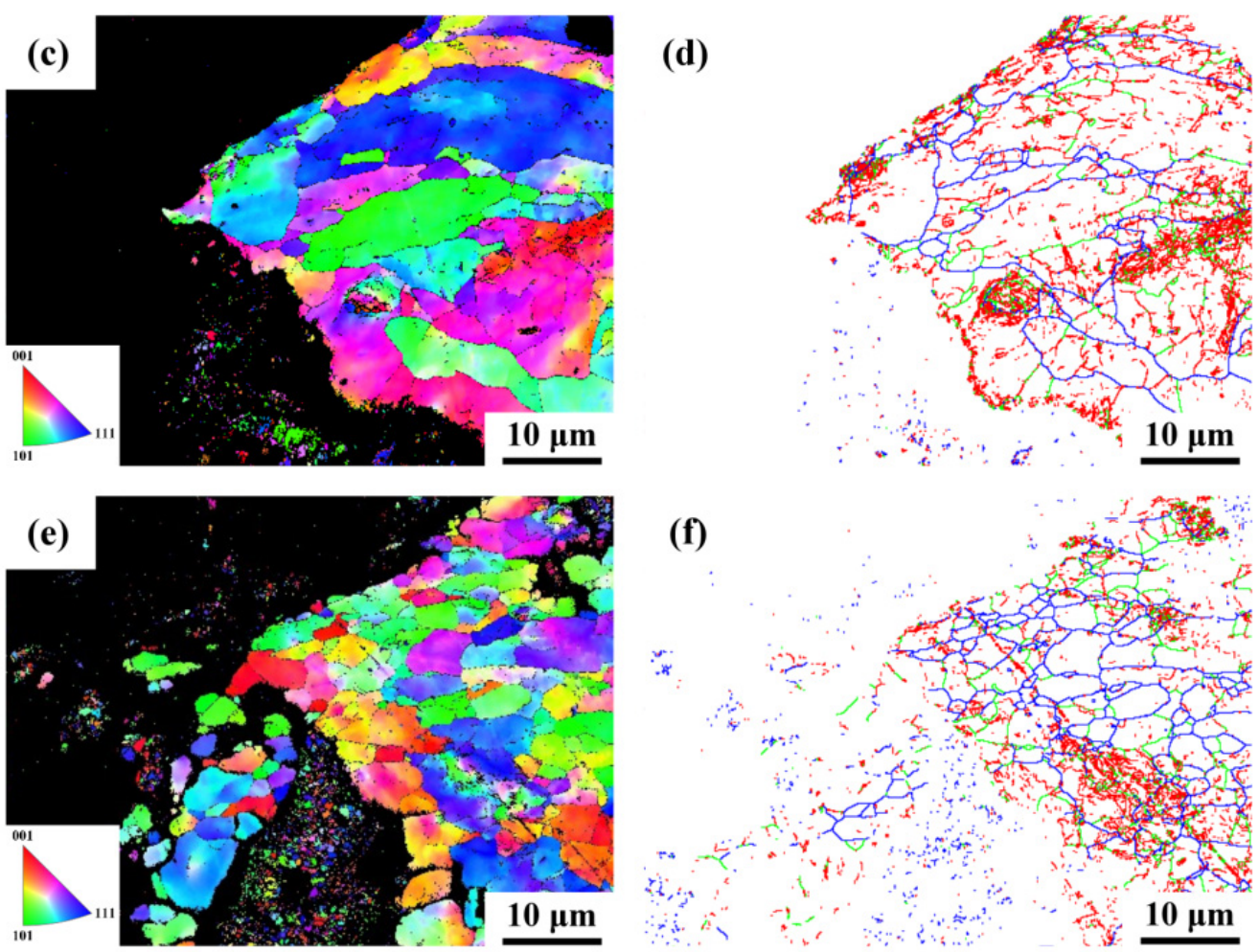

Figure 11. (a,c,e) The inverse pole figures, $(\mathbf{b}, \mathbf{d}, \mathbf{f})$ grain boundary maps of the fracture zone for the $(\mathbf{a}, \mathbf{b})$ WP specimen, (c,d) WP-800P specimen and (e,f) WP-860P specimen tested at $933 \mathrm{~K} / 80 \mathrm{MPa}$. $\left(\square: 1-5^{\circ}, \square:\right.$ : $\left.-15^{\circ}, \square: 15-62.5^{\circ}\right)$.

\section{Discussion}

The WM contained higher Mn and Ni but lower C contents than the Gr. 91 steel plate and tube. As compared with the steel plate, the $\mathrm{A}_{\mathrm{C} 1}$ and $\mathrm{A}_{\mathrm{C} 3}$ temperatures of the $\mathrm{WM}$ were about $30 \mathrm{~K}$ lower than those of the steel plate. The low $\mathrm{A}_{\mathrm{C} 1}$ temperature meant that the weld beads during multiple passes would undergo phase transformation easier than would the $\mathrm{BM}$. In addition, the low $\mathrm{A}_{\mathrm{C} 1}$ temperature of the WM would result in tempering the modified 91 heavy weld at a lower temperature range, which could be insufficient to restore the HAZ toughness and release the residual stress completely. Therefore, the effects of WM composition on the available temperature range for post-weld tempering and weld properties are worthy of further investigation, since they are less reported or investigated.

The microstructures of the tempered WM consisted of a solidified coarse structure with coarse martensite packets inside. TEM micrographs displayed that the elongated and spherodized carbides were present mainly along the lath boundaries of the tempered WM. Soft, island like $\delta$ ferrite was also seen in the Gr. $91 \mathrm{WM}$ in the as-welded and tempered conditions. The microstructural features of 
the over-tempered (WP-800) sample were similar to those of the W and WP samples. Polygonization tended to divide the wide laths into parallel short and fine laths in the WP-800P sample. Coarse grain sizes and martensite packets were completely replaced by a fine-grained structure in the simulated samples heated below the $\mathrm{A}_{\mathrm{C} 3}$ temperature, i.e., the WP-860 and WP-860P samples.

The recovered ferrite in the simulated HAZ is reported to have poor creep-rupture strength and increases of roughly two orders of magnitude in the minimum creep rate of the Gr. 91 steel [23]. Moreover, it was reported that creep cavities form mainly in the FGHAZ of a Gr. 91 steel weld, and scarcely in the WM, despite the presence of soft ferrite inside the WM [24]. It was deduced that the soft ferrite in the WM was harmful to the creep resistance, but the coarse structure of the WM contributed to it. It was also deduced that the coarse-grained structure of the WM dominated the creep fracture, resulting in a higher creep resistance than that of the steel base metal. Moreover, the fewer ferrite/tempered martensite interfaces in the WM also account for the low number of creep cavities in the Gr. $91 \mathrm{WM}$ [24]. Therefore, the amount of $\delta$ ferrite in the WM should be controlled or minimized to further improve its creep resistance/strength.

\section{Conclusions}

(1) The higher Mn and Ni but lower C contents of the WM than those of the Gr. 91 steel base metal accounted for the lower $\mathrm{A}_{\mathrm{C} 1}$ and $\mathrm{A}_{\mathrm{C} 3}$ temperatures of the WM. The microstructures of the WM consisted of a coarse solidified structure with coarse martensite packets inside. Elongated and spherodized $\mathrm{M}_{23} \mathrm{C}_{6}$ carbides were mainly present along the lath boundaries of the tempered WM. Even in the AW condition, island-like ferrite was formed in the WM.

(2) Different microstructures were observed in the simulated samples, depending on the applied thermal cycles. Overall, the microstructural features of the WP-800 and WP-800P samples were somehow similar to those of the W and WP samples. The occurrence of polygonization in the WP-800 sample tended to divide the coarse laths present in the WP sample into parallel short and fine laths. Moreover, coarse grain sizes and martensite packets were completely replaced by a fine-grained structure in the simulated samples heated below the $\mathrm{A}_{\mathrm{C} 3}$ temperature; i.e., the WP-860 and WP-860P samples.

(3) The short-term creep tests showed that the creep resistance of the tempered WM sample (WP) was much higher than that of the Gr. 91 base metal, and even that of the base metal normalized at $1333 \mathrm{~K}$. However, the applied thermal cycles could obviously degrade the creep resistance of the WM. The creep lives of the over-tempered (WP-800P) and partially transformed (WP-860P) samples were shortened significantly, particularly that of the WP-860P sample. The creep resistance of the reheated WM that underwent partial transformation was lower than those of the other zones in a multiple-pass weld.

Author Contributions: L.-W.T. organized this study and R.-K.S. help the EBSD and microstructural evaluation. C.-C.L., C.-C.W., and T.-C.C. performed all the tests. All authors were invited to complete the manuscript. All authors have read and agreed to the published version of the manuscript.

Funding: The authors appreciate the financial support of this study by the Ministry of Science and Technology, ROC (Contract No. MOST 106-2221-E-019-060-MY3).

Conflicts of Interest: The authors declare no conflict of interest.

\section{References}

1. Klueh, R.L.; Nelson, A.T. Ferritic/martensitic steels for next-generation reactors. J. Nucl. Mater. 2007, 371, 37-52. [CrossRef]

2. Brozda, J.; Zeman, M. Weldability of $9 \mathrm{Cr}-1 \mathrm{Mo}-\mathrm{Nb}, \mathrm{V}$ P91 steel intended for service in the power industry. Weld. Int. 1996, 10, 370-380. [CrossRef] 
3. Ning, B.Q.; Yan, Z.S.; Fu, J.C.; Bie, L.J.; Liu, Y.C. Effect of cooling rate on phase transformation process and microstructure of T91 ferritic heat resistant steel. J. Nucl. Mater. 2009, 393, 71-75.

4. Gao, Q.Z.; Di, X.J.; Liu, Y.C.; Yan, Z.S. Recovery and recrystallization in modified 9Cr-1Mo steel weldments after post-weld heat treatment. Int. J. Pres. Ves. Pip. 2012, 93, 69-74. [CrossRef]

5. Sireesha, M.; Sundaresan, S.; Albert, S.K. Microstructure and mechanical properties of weld fusion zones in modified 9Cr-1Mo steel. J. Mater. Eng. Perform. 2001, 10, 320-330. [CrossRef]

6. Pandey, C.; Mahapatra, M.M. Effect of heat treatment on microstructure and hot impact toughness of various zones of P91 welded pipes. J. Mater. Eng. Perform. 2016, 25, 2195-2210. [CrossRef]

7. Samuel, E.I.; Choudhary, B.K.; Rao, K.B.S. Influence of post-weld heat treatment on tensile properties of modified 9Cr-1Mo ferritic steel base metal. Mater. Sci. Technol. 2007, 23, 992-999. [CrossRef]

8. Singh, D.; Sharma, M.; Gill, J. Effect of post weld heat treatment on the impact toughness and microstructural property of P-91 steel weldment. Int. J. Res. Mech. Eng. Technol. 2013, 3, $216-219$.

9. Arivazhagan, B.; Prabhu, R.; Albert, S.K.; Kamaraj, M.; Sundaresan, S. Microstructure and mechanical properties of $9 \mathrm{Cr}-1 \mathrm{Mo}$ steel weld fusion zones as a function of weld metal composition. J. Mater. Eng. Perform. 2009, 18, 999-1004. [CrossRef]

10. Silwal, B.; Li, L.; Deceuster, A.; Griffiths, B. Effect of post weld heat treatment on the toughness of heat-affected zone for grade 91 steel. Weld. J. 2013, 92, 80s-87s.

11. Zhang, Z.Y.; Holloway, G.; Marshall, A. Properties of T/P92 weld metals for ultra super critical (USC) power plant. Int. J. Microstruct. Mater. Prop. 2011, 6, 20-39. [CrossRef]

12. Francis, J.A.; Mazur, W.; Bhadeshia, H.K.D.H. Review type IV cracking in ferritic power plant steels. J. Mater. Sci. Technol. 2006, 22, 1387-1395. [CrossRef]

13. Tsuchida, Y.; Okamoto, K.; Tokunaga, Y. Study of creep rupture strength in heat affected zone of 9Cr-1Mo-V-Nb-N steel by welding thermal cycle simulation. Weld. Int. 1996, 10, 454-460. [CrossRef]

14. Wojsyk, K.; Golański, G.; Jasak, J.; Słania, J.; Zieliński, A.; Urbańczyk, P. Influence of the annealing time after welding on the mechanical properties of welded joint of T91 steel. Arch. Metall. Mater. 2016, 61, 1425-1430. [CrossRef]

15. Laha, K.; Chandravathi, K.S.; Parameswaran, P.; Rao, K.B.S. Type IV cracking susceptibility in weld joints of different grades of Cr-Mo ferritic steel. Metall. Mater. Trans. A 2009, 40, 386-397. [CrossRef]

16. Wang, Y.Y.; Li, L.J. Microstructure evolution of fine-grained heat-affected zone in type IV failure of P91 welds. Weld. J. 2016, 95, 27-36.

17. Das, C.R.; Albert, S.K.; Bhaduri, A.K.; Srinivasan, G.; Murty, B.S. Effect of prior microstructure on microstructure and mechanical properties of modified $9 \mathrm{Cr}-1 \mathrm{Mo}$ steel weld joints. Mater. Sci. Eng. A 2008, 477, 185-192. [CrossRef]

18. Hongo, H.; Tabuchi, M.; Watanabe, T. Type IV creep damage behavior in Gr. 91 steel welded joints. Metall. Mater. Trans. A 2012, 43, 1163-1173. [CrossRef]

19. Divya, M.; Das, C.R.; Albert, S.K.; Goyal, S.; Ganesh, P.; Kaul, R.; Bhaduri, A.K. Influence of welding process on type IV cracking behavior of P91 steel. Mater. Sci. Eng. A 2014, 613, 148-158. [CrossRef]

20. Wang, Y.Y.; Li, L.J.; Kannan, R. Transition from type IV to type I cracking in heat-treated grade 91 steel weldments. Mater. Sci. Eng. A 2018, 714, 1-13. [CrossRef]

21. Wu, H.W.; Wu, T.J.; Shiue, R.K.; Tsay, L.W. The Effect of normalizing temperature on the short-term creep rupture of the simulated HAZ in Gr. 91 steel welds. Metals 2018, 8, 1072. [CrossRef]

22. Wu, T.J.; Liao, C.C.; Chen, T.C.; Shiue, R.K.; Tsay, L.W. Microstructural evolution and short-term creep rupture of the simulated HAZ in T92 steel normalized at different temperatures. Metals 2019, 9, 1310. [CrossRef]

23. Totemeier, T.C.; Tian, H.; Simpson, J.A. Effect of normalization temperature on the creep strength of modified 9Cr-1Mo steel. Metall. Mater. Trans. A 2006, 37, 1519-1525. [CrossRef]

24. Xu, J.; Zhong, X.Y.; Shoji, T.S.; Tatsuki, T.; Matsumura, Y.; Nakashima, M. Characterizations of the microstructure of $9 \mathrm{Cr}-1 \mathrm{Mo}$ steel weld joint after long-term service in a supercritical fossil power plant. Metall. Mater. Trans. A 2018, 49, 4700-4709. [CrossRef]

25. Mythili, R.; Thomas Paul, V.; Saroja, S.; Vijayalakshmi, M.; Raghunathan, V.S. Microstructural modification due to reheating in multipass manual metal arc welds of 9Cr-1Mo steel. J. Nucl. Mater. 2003, 312, 199-206. [CrossRef] 
26. Hsiao, T.H.; Chen, T.C.; Jeng, S.L.; Chung, T.J.; Tsay, L.W. Effects of simulated microstructure on the creep rupture of the modified 9Cr-1Mo steel. J. Mater. Eng. Perform. 2016, 25, 4317-4325. [CrossRef]

27. Czyrska-Filemonowicz, A.; Zielińska-Lipiec, A.; Ennis, P.J. Modified 9\% Cr steels for advanced power generation: Microstructure and properties. J. Achiev. Mater. Manuf. Eng. 2006, 19, 43-48.

(C) 2020 by the authors. Licensee MDPI, Basel, Switzerland. This article is an open access article distributed under the terms and conditions of the Creative Commons Attribution (CC BY) license (http://creativecommons.org/licenses/by/4.0/). 